\title{
Thyroid follicular carcinoma-like renal tumor: a case report with morphologic, immunophenotypic, cytogenetic and scintigraphic studies
}

William Sterlacci • Irmgard Verdorfer •

Michael Gabriel • Gregor Mikuz

Published online: 12 March 2008

(C) Springer-Verlag 2008

Erratum to: Virchows Arch

DOI 10.1007/s00428-007-0486-4

Unfortunately, the author names were published incorrectly.

The online version of the original article can be found at http://dx.doi. org/10.1007/s00428-007-0486-4.

W. Sterlacci $(\bowtie) \cdot$ I. Verdorfer $\cdot$ G. Mikuz

Department of Pathology, Medical University of Innsbruck,

Muellerstr. 44,

6020 Innsbruck, Austria

e-mail: william.sterlacci@i-med.ac.at

M. Gabriel

Department of Nuclear Medicine,

Medical University of Innsbruck,

Anichstr. 35,

Innsbruck, Austria 